\title{
Effect of Internal Radiant Heat Transfer on Temperature Distribution, Thermal Stress, and Deflection in Box Beams ${ }^{1}$
}

\author{
Stanley Goodman, Stanton B. Russell, and Charles E. Noble
}

\begin{abstract}
Thirteen box beams were analyzed to determine the effect of internal radiant heat transfer on temperature distribution, thermal stress, and deflection. A rough experimental check of temperature distribution and beam deflection was made for one case. For maximum beam temperatures above $700^{\circ}$ to $900^{\circ} \mathrm{F}$, change in emittance of the interior surfaces of the beam had an appreciable effect on the cover (but not the web) temperatures and to an even greater extent, on the beam deflection. At maximum beam temperatures of $1,200^{\circ} \mathrm{F}$, an increase in interior surface emittance appreciably relieved the maximum thermal stress.
\end{abstract}

\section{Introduction}

The subjection of aircraft and other structures to increasingly high temperatures gives rise to a need for predicting the transient temperature distribution in the structures, and the resulting thermal stresses and deformations. This knowledge will make possible the rational design of the structure, and the devising of methods of alleviating thermal stresses and deflections.

As the temperature of a structure increases, radiation becomes more important as a mode of heat transfer [1]. ${ }^{2}$ The influence of radiant heat transfer on the temperature distribution of the structure is affected by structural geometry, heating rate, and thermal properties of the beam material. The purpose of this investigation was to determine the effect of changing the emittance of the interior surfaces of a box beam on temperature distribution, maximum thermal stress, and beam deflection in heated box beams.

\section{Structures and Material}

Thirteen analyses were made of modifications of three basic types of box beams. The beam cross sections are shown in the figure at the top of table 1 ; wall thicknesses are indicated by the ratios listed in columns 2 and 3 of the table. One type (cases 1, 2, and 3 ) is a thick-walled beam, similar to a beam used in the experimental work. The other types are typical of beams used in aircraft structures; one type is relatively thick-walled (cases 4 to 8 ) and the other relatively thin-walled (cases 9 to 13 ).

Thermal and elastic properties were taken as those of the type 302 stainless-steel test beam. Thermal conductivity and specific heat were approximated by the linear relationships:

$$
\begin{aligned}
& k=7.08+0.0043 T \\
& c=0.106+0.0000257 T,
\end{aligned}
$$

1 This work was conducted at the National Bureau of Standards under the sponsorsh ip and with the financial assistance of the Office of Naval Research.

2 Figures in brackets indicate the literature references a the end $c$ this paper. where $k$ is thermal conductivity $\left(\mathrm{Btu} / \mathrm{hr} \mathrm{ft}^{\circ} \mathrm{F}\right)$; $c$ is specific heat $\left(\mathrm{Btu} / \mathrm{lb}^{\circ} \mathrm{F}\right)$; and $T$ is absolute temperature $\left({ }^{\circ} \mathrm{R}\right)$. Hemispherical total emittance was taken as 0, 0.35 (emittance of the test beam, cases 1 to 3 ) and 1 , as indicated in columns 4 and 5 of table 1 .

Young's modulus and the coefficient of linear thermal expansion were represented by

$$
\begin{aligned}
& E=31.0 \times 10^{6}-0.0064 T \times 10^{6} \\
& \alpha=8.29 \times 10^{-6}+0.00137 T \times 10^{-6},
\end{aligned}
$$

where $E$ is Young's modulus (lb/in. $\left.{ }^{2}\right), \alpha$ is coefficient of linear thermal expansion (in./in. ${ }^{\circ} \mathrm{F}$ ), and $T$ is absolute temperature $\left({ }^{\circ} \mathrm{R}\right)$.

\section{Boundary Conditions}

The beams were assumed to be subjected to a uniform heat input along one cover in a rarefied atmosphere. The heating rates are listed in columns 6 and 7 of table 1 . The initial beam temperature was assumed to be $78^{\circ} \mathrm{F}$. For the test beam (cases 1, 2, 3), the boundary condition was taken as the heated cover temperature (figs. 2 and 7) observed in an experiment. For all other cases, the boundary condition was taken as the assumed heat input to the cover. All elements of the heated cover were assumed to remain constant at $1,200^{\circ} \mathrm{F}$ after reaching that temperature.

\section{Method of Analysis}

\subsection{Calculation of Temperature Distribution}

Analysis was made by a numerical method similar to that described by Dusinberre [2]. The beam cross section was divided into analysis elements, and a heat-balance equation was set up for each analysis element and solved for the element temperature after a short time interval, $\Delta \theta$. The process was repeated for successive short-time intervals using the new element temperatures as the starting point of the next computation. It 
TABLE 1. Computed cover temperatures, maximum thermal stress and maximum deflection in box beams heated along one cover

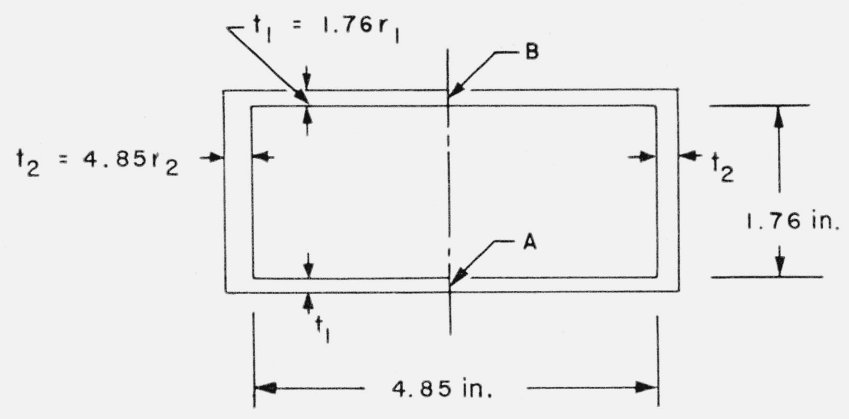

\begin{tabular}{|c|c|c|c|c|c|c|c|c|c|c|c|c|}
\hline \multirow{3}{*}{$\begin{array}{c}\text { Case } \\
\\
\\
\\
1 \\
2 \\
3\end{array}$} & \multirow{3}{*}{$\begin{array}{c}\mathrm{r}_{1} \\
\\
0.0727 \\
.0727 \\
.0727\end{array}$} & \multirow{3}{*}{$\begin{array}{c}\mathrm{r}_{2} \\
\\
0.0264 \\
.0264 \\
.0264\end{array}$} & \multicolumn{2}{|c|}{ Surface emittance } & \multirow{2}{*}{\multicolumn{2}{|c|}{ Heating rate }} & \multirow{3}{*}{$\begin{array}{c}\begin{array}{c}\text { Elapsed } \\
\text { time }\end{array} \\
\\
\text { sec } \\
378 \\
378 \\
378\end{array}$} & \multicolumn{2}{|c|}{ Temperature b at } & \multicolumn{2}{|c|}{ Maximum stress c } & \multirow{3}{*}{$\begin{array}{c}\begin{array}{c}\text { Maximum } \\
\text { defiection } \mathrm{cd}\end{array} \\
\begin{array}{l}\text { in./in. }{ }^{2} \\
0.46 \times 10^{-3} \\
.42 \\
30\end{array}\end{array}$} \\
\hline & & & \multirow{2}{*}{$\begin{array}{l}\text { Interior } \\
\\
\quad \begin{array}{l}0 \\
0.35 \\
1\end{array}\end{array}$} & \multirow{2}{*}{$\begin{array}{c}\text { Exterior } \\
\\
\\
0.35 \\
.35 \\
.35\end{array}$} & & & & $A$ & $B$ & Tensile & Compressive & \\
\hline & & & & & Btu/hr ft ${ }^{2}$ & $\begin{array}{l}{ }^{\circ} \mathrm{F} / \mathrm{sec} \text { a } \\
3.8 \\
3.8 \\
3.8\end{array}$ & & $\begin{array}{l}\circ F \\
958 \\
958 \\
958\end{array}$ & $\begin{array}{r}\circ F \\
84 \\
147 \\
377\end{array}$ & $\begin{array}{l}\quad p s i \\
35.3 \times 10^{3} \\
35.8 \\
34.8\end{array}$ & $\begin{array}{l}\quad p s i \\
\text { 29. } 3 \times 10^{3} \\
29.7 \\
30.5\end{array}$ & \\
\hline $\begin{array}{l}4 \\
5 \\
6\end{array}$ & $\begin{array}{l}.02 \\
.02 \\
.02\end{array}$ & $\begin{array}{l}.03 \\
.03 \\
.03\end{array}$ & $\begin{array}{l}0 \\
0.35 \\
1\end{array}$ & $\begin{array}{l}.35 \\
.35 \\
.35\end{array}$ & $\begin{array}{l}32400 \\
32400 \\
32400\end{array}$ & $\begin{array}{l}50 \\
50 \\
50\end{array}$ & $\begin{array}{l}26.6 \\
26.6 \\
26.6\end{array}$ & $\begin{array}{l}1202 \\
1173 \\
1095\end{array}$ & $\begin{array}{r}78 \\
101 \\
188\end{array}$ & $\begin{array}{l}121.7 \\
118.0 \\
108.5\end{array}$ & $\begin{array}{l}127.9 \\
124.4 \\
116.1\end{array}$ & $\begin{array}{l}.49 \\
.47 \\
.41\end{array}$ \\
\hline $\begin{array}{l}7 \\
8\end{array}$ & $\begin{array}{l}.02 \\
.02\end{array}$ & $\begin{array}{l}.03 \\
.03\end{array}$ & $\begin{array}{r}0.35 \\
.35\end{array}$ & $\begin{array}{l}0 \\
1\end{array}$ & $\begin{array}{l}32400 \\
32400\end{array}$ & $\begin{array}{l}50 \\
50\end{array}$ & $\begin{array}{l}26.6 \\
26.6\end{array}$ & $\begin{array}{l}1200 \\
1104\end{array}$ & $\begin{array}{r}102 \\
98\end{array}$ & $\begin{array}{l}121.5 \\
111.0\end{array}$ & $\begin{array}{l}127.1 \\
116.7\end{array}$ & $\begin{array}{l}.48 \\
.44\end{array}$ \\
\hline $\begin{array}{r}9 \\
10 \\
11\end{array}$ & $\begin{array}{l}.01 \\
.01 \\
.01\end{array}$ & $\begin{array}{l}.01 \\
.01 \\
.01\end{array}$ & $\begin{array}{l}0 \\
0.35 \\
1\end{array}$ & $\begin{array}{r}0.35 \\
.35 \\
.35\end{array}$ & $\begin{array}{l}10800 \\
10800 \\
10800\end{array}$ & $\begin{array}{l}30 \\
30 \\
30\end{array}$ & $\begin{array}{l}45 \\
45 \\
45\end{array}$ & $\begin{array}{r}1204 \\
1135 \\
959\end{array}$ & $\begin{array}{r}78 \\
154 \\
371\end{array}$ & $\begin{array}{r}102.9 \\
92.1 \\
71.5\end{array}$ & $\begin{array}{l}99.0 \\
91.0 \\
74.9\end{array}$ & $\begin{array}{l}.58 \\
.51 \\
.34\end{array}$ \\
\hline $\begin{array}{l}12 \\
13\end{array}$ & $\begin{array}{l}.01 \\
.01\end{array}$ & $\begin{array}{l}.01 \\
.01\end{array}$ & $\begin{array}{l}0 \\
1\end{array}$ & $\begin{array}{l}.35 \\
.35\end{array}$ & $\begin{array}{l}32400 \\
32400\end{array}$ & $\begin{array}{l}91 \\
91\end{array}$ & $\begin{array}{l}13.7 \\
13.7\end{array}$ & $\begin{array}{l}1200 \\
1125\end{array}$ & $\begin{array}{r}78 \\
203\end{array}$ & $\begin{array}{l}127.6 \\
114.5\end{array}$ & $\begin{array}{r}101.1 \\
95.1\end{array}$ & $\begin{array}{l}.58 \\
.49\end{array}$ \\
\hline
\end{tabular}

a Approximate temperature rise rate at point $A$ up to about $800^{\circ} \mathrm{F}$.

b Initial temperature $78^{\circ} \mathrm{F}$.

c Neglecting yielding, creep, and buckling.

d Deflection per unit beam length squared.

was assumed that surface emittance remained constant and that beam surfaces reflected diffusely and were gray, i.e., total emittance and absorptance are equal at all beam temperatures. Gaseous heat transfer was neglected.

One-half of the cross section of the symmetrical beam was divided into 12 analysis elements. Since the external heat transfer was symmetrical with respect to the left and right halves of the beam cross section, the right half of the beam was represented by a perfect but diffuse reflector. The reflector was divided into four regions. The element configuration for cases 1,2 , and 3 , shown in figure 1 , is typical of all cases.

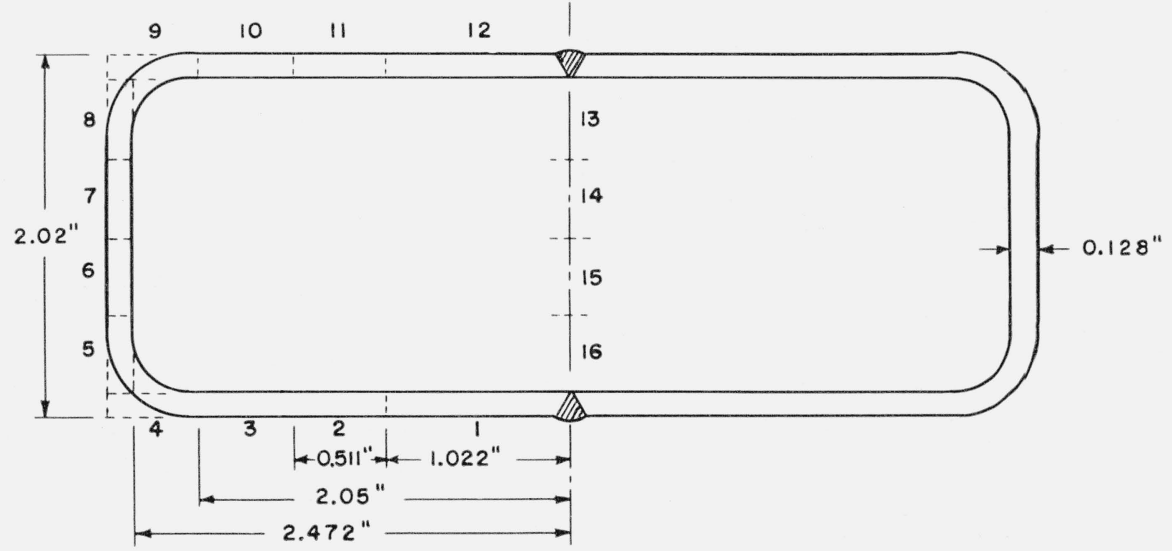

FIGURE 1. Test beam cross section (cases 1, 2,3).

Material: Stainless steel, 18-8 (302); length: 30 in.; analysis elements designated by dotted lines and small numerals. 
The heat balance equation is as follows:

$$
\begin{aligned}
T_{m}^{\prime} & =T_{m}+\frac{\Delta \theta}{V_{m} \rho C_{m}}\left\{\left(k_{m-1, m}\right)\left(H_{m}\right)\left(T_{m-1}-T_{m}\right)\right. \\
& +\left(k_{m, m+1}\right)\left(J_{m}\right)\left(T_{m+1}-T_{m}\right)+\epsilon_{m} \sigma A_{m}\left(T_{A}^{4}-T_{m}^{4}\right) \\
& +\sigma A_{m}^{\prime}\left[F_{m, 1}\left(T_{1}^{4}-T_{m}^{4}\right)+F_{m, 2}\left(T_{2}^{4}-T_{m}^{4}\right)+\ldots\right. \\
& \left.\left.+F_{m, 12}\left(T_{12}^{4}-T_{m}^{4}\right)\right]+W_{m}\right\},
\end{aligned}
$$

where

$T_{m}^{\prime}$ is the temperature $\left({ }^{\circ} \mathrm{R}\right)$ at the center of element $m$ after time interval $\Delta \theta$

$V_{m}$ is the volume $\left(\mathrm{ft}^{3}\right)$ of element $m$

$T_{m}$ is the temperature $\left({ }^{\circ} \mathrm{R}\right)$ at the center of element $m$ at the beginning of the time interval $\Delta \theta$

$\rho$ is the density of the material $\left(\mathrm{lb} / \mathrm{ft}^{3}\right)$

$C_{m}$ is the specific heat of element $m\left(\mathrm{Btu} / \mathrm{lb}{ }^{\circ} \mathrm{F}\right)$, represented by a linear function of $T_{m}$.

$k_{m}, m+1, k_{m-1}, m$, are the thermal conductivities of the beam metal at the mean temperatures of the elements $m$ and $m+1$, and $m$ and $m-1$, respectively $\left(\mathrm{Btu} / \mathrm{hr} \mathrm{ft}^{\circ} \mathrm{F}\right)$

$H_{m}, J_{m}$ are ratios of element contact areas to distances between element centers for element $m$ and adjacent elements $m-1, m+1$, respectively (ft)

$\epsilon_{m}$ is hemispherical total emittance of element surface $m$

$\sigma$ is the Stefan-Boltzmann constant $\left(0.1713 \times 10^{-8}\right)$ in $\mathrm{Btu} / \mathrm{ft}^{2} \mathrm{hr}^{\circ} \mathrm{R}^{4}$

$A_{m}$ is exterior surface area $\left(\mathrm{ft}^{2}\right)$ of element $m$

$T_{A}$ is ambient temperature $\left({ }^{\circ} \mathrm{R}\right)$

$A_{m}^{\prime}$ is interior surface area $\left(\mathrm{ft}^{2}\right)$ of element $m$

$F_{m, n}$ is an over-all radiant heat interchange factor for net radiant heat exchange between a gray surface of element $m$ and a gray surface of element $n$. It includes the effect of direct and all reflected radiation.

$W_{m}$ is the external heat input (Btu/hr).

The first two terms inside the brackets on the right-hand side of eq (5) represent conductive heat transfer between element $m$ and adjacent elements; the third term represents radiant heat transfer with the outside environment, the fourth term represents internal radiant heat exchange between element $m$ and the rest of the beam interior; the fifth term represents the assumed heat input boundary condition. For cases 1, 2, and 3 in which the boundary condition was taken as the observed heated cover temperature history of the test beam, the temperature of each heated cover element was expressed by four linear functions of time covering successive time intervals.

To compute the graybody radiant heat exchange factors, $F$, blackbody radiant heat exchange factors were computed for all two-element combinations of the 16 internal surfaces of the analysis elements and (fictitious) reflector using the methods of reference [3], and radiation geometry. Values of the $256 \mathrm{~F}$ 's were then obtained from the matrix relationships of reference [4]. The computations were performed on SEAC using an existing code for inverting the matrices.

The temperature-distribution computations were computed on SEAC. Temperatures at the midpoints of the 12 analysis elements of the beam were printed out at regular time intervals which were whole number multiples of $\Delta \theta$.

In order to minimize computing machine running time, it was desirable to use the largest value of the time interval, $\Delta \theta$, consistent with adequate accuracy of solution. The time interval must be sufficiently short that during the interval (1) The initial element temperatures can be used with negligible error and (2) for conductive heat transfer; the effect of any nonadjacent element on a given element is negligible. Satisfactory values of $\Delta \theta$ were obtained by trial. A portion of the temperature distribution history was computed several times using successively larger values of $\Delta \theta$. The largest value of $\Delta \theta$ which gave a temperature distribution history negligibly different from that obtained with the smallest value of $\Delta \theta$ was used to compute the complete temperature distribution history. Values of $\Delta \theta$ found satisfactory by this method ranged from $0.72 \mathrm{sec}$ for rapidly heated beams to $1.8 \mathrm{sec}$ for slowly heated beams.

Some error was generated in the beam temperature history computations by representing one-half of the beam cross section by a perfect, diffuse rather than specular, reflector. As a check on the magnitude of this error, radiant heat transfer rates were computed for a simple symmetrical case using first the entire beam cross section in the computations, and then an equivalent beam consisting of one-half of the beam cross section and a diffuse reflector. An infinitely long box beam of rectangular cross section divided into six analysis elements was used. The beam was 2 -in. deep, 8 -in. wide, and emissivity was 0.35 . The vertical (2-in.) walls of the beam were at temperature $T_{1}$ and the horizontal walls at absolute zero. The rate of radiant heat transfer to the left half of the upper horizontal wall was

$$
\begin{array}{ll}
q=0.1354 \sigma T_{1}^{4} & \text { for original beam } \\
q=0.1389 \sigma T_{1}^{4} & \begin{array}{r}
\text { for equivalent beam } \\
\text { with diffuse reflector, }
\end{array}
\end{array}
$$

where $q$ is rate of radiant heat transfer $\left(\mathrm{Btu} / \mathrm{hr} \mathrm{ft}^{2}\right)$; $\sigma$ is the Stefan-Boltzmann constant $\left(0.1713 \times 10^{-8}\right.$ $\left.\mathrm{Btu} /\left(\mathrm{ft}^{2} \mathrm{hr}^{\circ} \mathrm{R}^{4}\right)\right)$; and $T_{1}$ is vertical wall temperature $\left({ }^{\circ} \mathrm{R}\right)$. It was concluded that the error due to use of a diffuse rather than a specular reflector was small.

\subsection{Computation of Thermal Stress and Deflection}

Thermal stresses and deflections in the beam were computed by the methods described in reference [5]. Integrations over the beam cross section were performed numerically using finite elements identical 
with those used in the temperature distribution computations (fig. 1). Possible effects of yielding, creep, and buckling were neglected.

\section{Test of Beam}

The test specimen, corresponding to case 2, table 1 , was a box beam constructed of 0.128 -in.-thick type 302 stainless-steel sheet (fig. 1). Two pieces of sheet were each bent into identical channel shapes and butt welded together lengthwise to form the $2 \mathrm{in.} \mathrm{by} 5 \mathrm{in.} \mathrm{by} 30$ in. beam.

The beam was heated in a vacuum chamber whose pressure was maintained at $4 \mathrm{~mm}$ of mercury, a pressure low enough to eliminate appreciable convective heat transfer. Only one cover of the beam was subjected to heating. It was heated with 12 quartz-tube, tungsten-filament heating elements uniformly spaced in a reflector. Total output of the heaters was $5.7 \mathrm{Btu} / \mathrm{sec}$. The reflector, a rectangular silver-plated stainless-steel channel enclosing the heating elements, confronted the heated cover of the beam. The reflectance of the reflector surface was about 0.97 .

Temperatures were measured at the center cross section on the heated cover of the beam, at the center cross section on the unheated cover, at two points on the heated cover $1 \mathrm{in}$. from one end, and at one point on the heated cover $1 \mathrm{in}$. from the other end. The temperatures were measured with ironconstantan thermocouples whose outputs were indicated by galvanometers. The thermocouples were calibrated before and after the test. The temperature rise of the heated cover was approximately 12 percent less at the beam ends than at the center cross section. The experimentally determined heated cover temperatures, which were used as the boundary condition in cases 1,2 , and 3 , are shown in figure 2 and, together with observed temperatures for two points on the opposite cover, in figure 7 .

The normal total emittance of the type 302 stainless steel was determined by comparing its rate of radiation at a given temperature with that of a silicon carbide bar at the same temperature. The radiation rates were determined by focusing the images of equal areas of the silicon carbide bar and of the stainless steel successively on a thermopile, using a fluorite lens. The emittance of the stainless steel obtained was constant in the temperature range $400^{\circ}$ to $1,000^{\circ} \mathrm{F}$ and equal to 0.35 .

Beam deflection at the center cross section was measured by means of SR-4 type AB-5 electrical strain gages mounted back-to-back on a shielded cantilever beam which was deflected by displacement of the center of the beam relative to its ends. Contact of the center of the beam with the cantilever was made by a Vycor rod. Calibration was accomplished by deflecting the cantilever by known amounts at the point of contact with a micrometer screw.

The maximum deflection observed was 0.415 in. after $240 \mathrm{sec}$ of heating. After 378 sec of heating the center deflection was 0.37 in.

\section{Results}

\subsection{Beam-Temperature Distribution}

Computed temperature histories at point $A$, in the center of the heated cover and at point $B$, in the center of the opposite cover (see sketch on table 1) are shown in figures 2 to 6 for the 13 cases considered. Figure 7 shows the computed temperature distribution in a thick-walled beam (cases 1, 2, 3) of the same dimensions as the test beam after 148, 189, and 297 sec of heating. Figure 8 shows the temperature distribution in a thin-walled beam after $45 \mathrm{sec}$ of slow heating, and after 13.7 sec of fast heating. Temperatures at $A$ and $B$ are listed in columns 9 and 10 of table 1. Comparison was made of geometrically similar beams heated at the same rate for the same length of time but having the following different values of interior or exterior emittances: 0 , 0.35 , and 1.0 .

It was found that, in all cases considered, a change in emittance of the surfaces had an appreciable effect on the cover temperatures and little on the web temperatures when the maximum heated cover temperature was above $700^{\circ}$ to $900^{\circ} \mathrm{F}$. For beams with the heated cover at a temperature of about $1,200^{\circ} \mathrm{F}$, changing the internal emittance from 0 to 1.0 reduced the temperature difference, $d$, between points $A$ and $B$ by 18 percent for the thin-walled beam with the cover heated at $91^{\circ} \mathrm{F} / \mathrm{sec}$, and by 48 percent for the same beam with one cover heated at $30^{\circ} \mathrm{F} / \mathrm{sec}$. For the same cover-heating rate the effect of change in interior emittance was less for the thicker-walled beam.

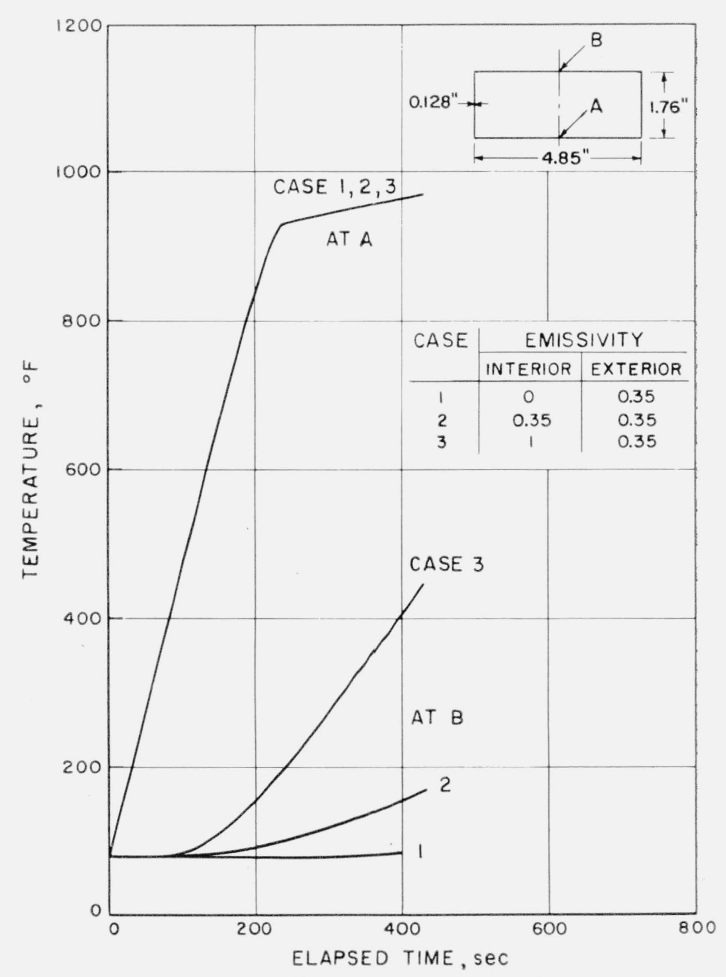

Figure 2. Beam temperature history. 


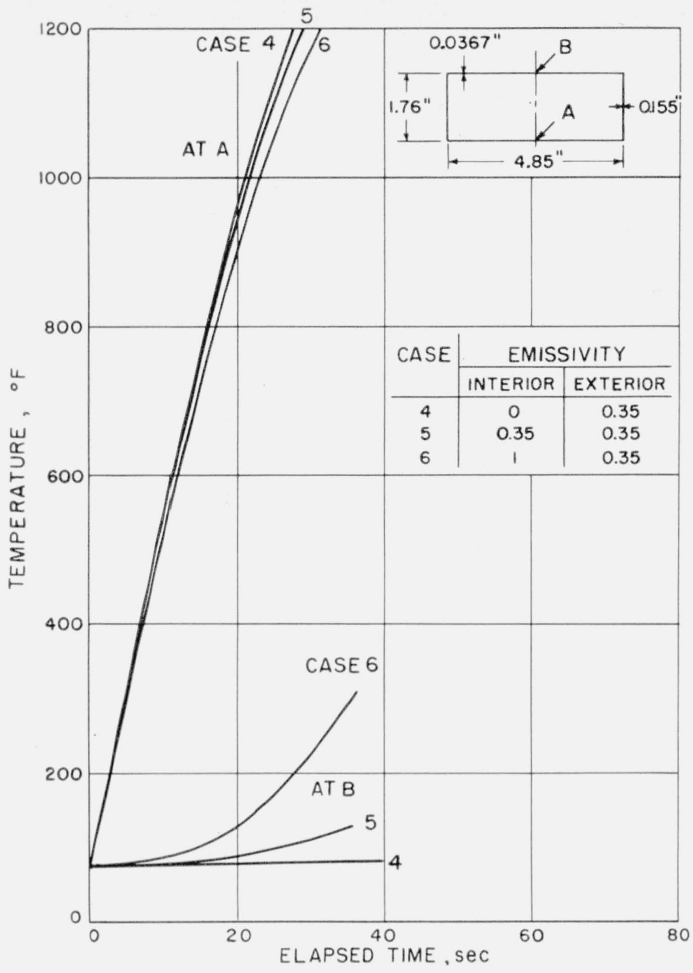

FIGURE 3. Beam temperature history for heating rate of 32,400 $B t u / h r f t^{2}$.

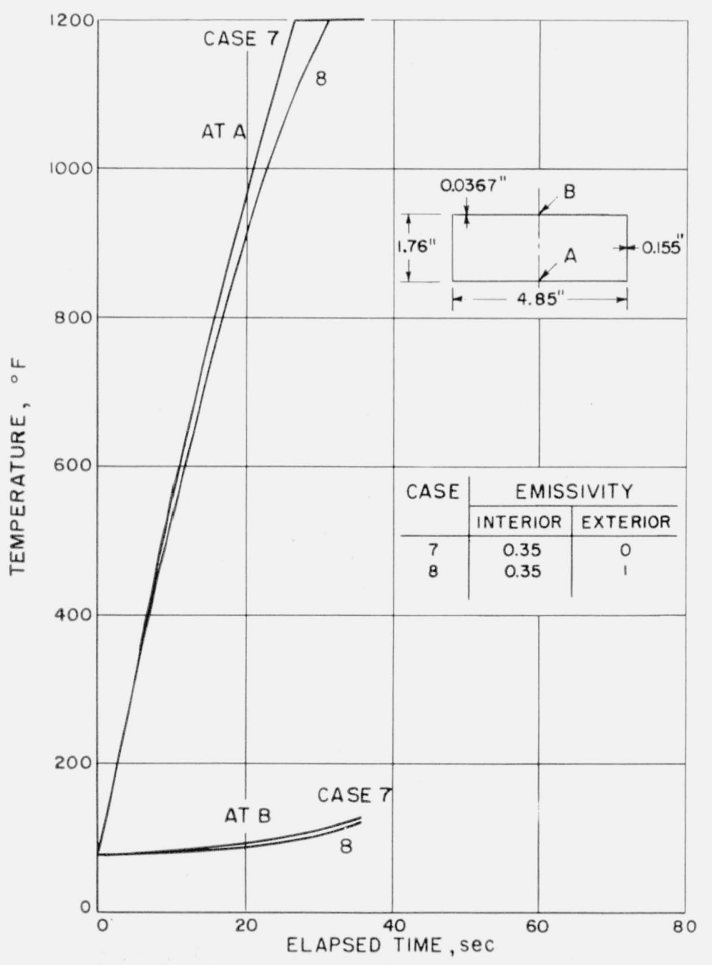

FIGURE 4. Beam temperature history for heating rate of 32,400 Btu/hr ft ${ }^{2}$.

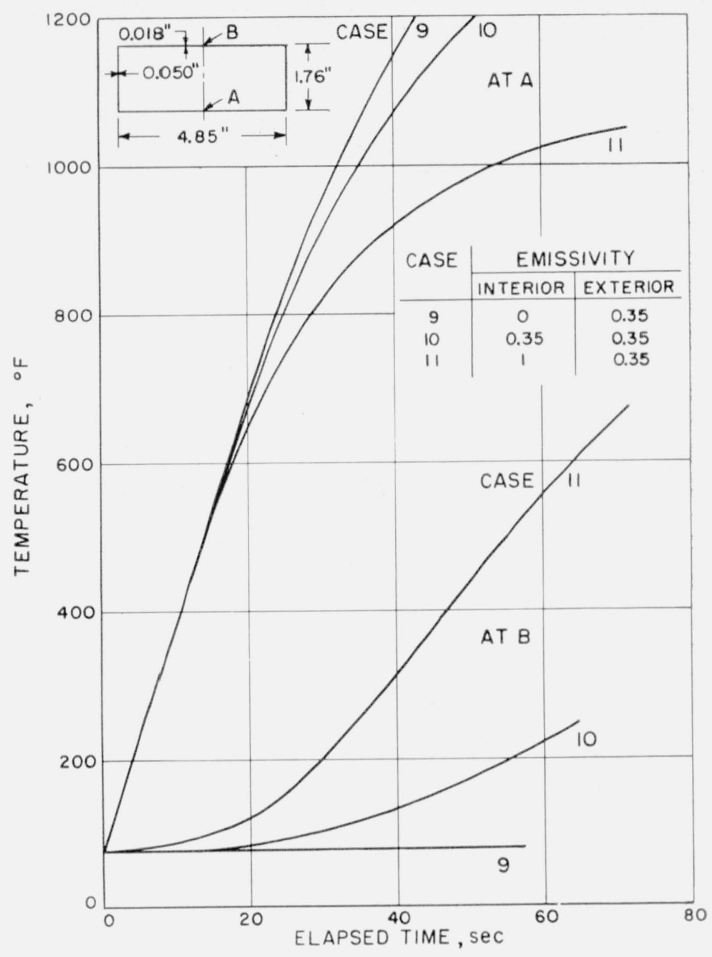

FiguRe 5. Beam temperature history for heating rate of 10,800 Btu/hr $f t^{2}$.

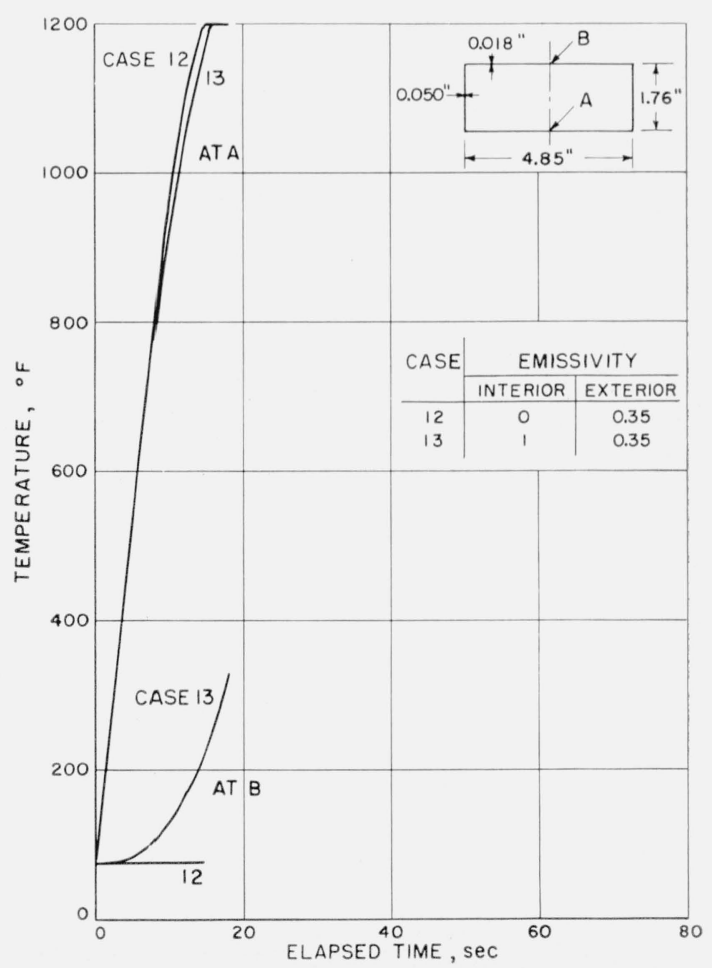

FiguRE 6. Beam temperature history for heating rate of 32,400 $B t u / h r t^{2}$. 
A change in exterior surface emittance has less effect on $d$ than a change in interior surface emittance. Comparison of cases 4 and 6 with corresponding cases 7 and 8 indicates that, for the particular conditions specified in table 1, increasing the interior surface emittance from 0 to 1.0 causes a decrease in $d$ of 19 percent; increasing the exterior surface emittance from 0 to 1.0 causes a decrease in $d$ of only 8 percent.

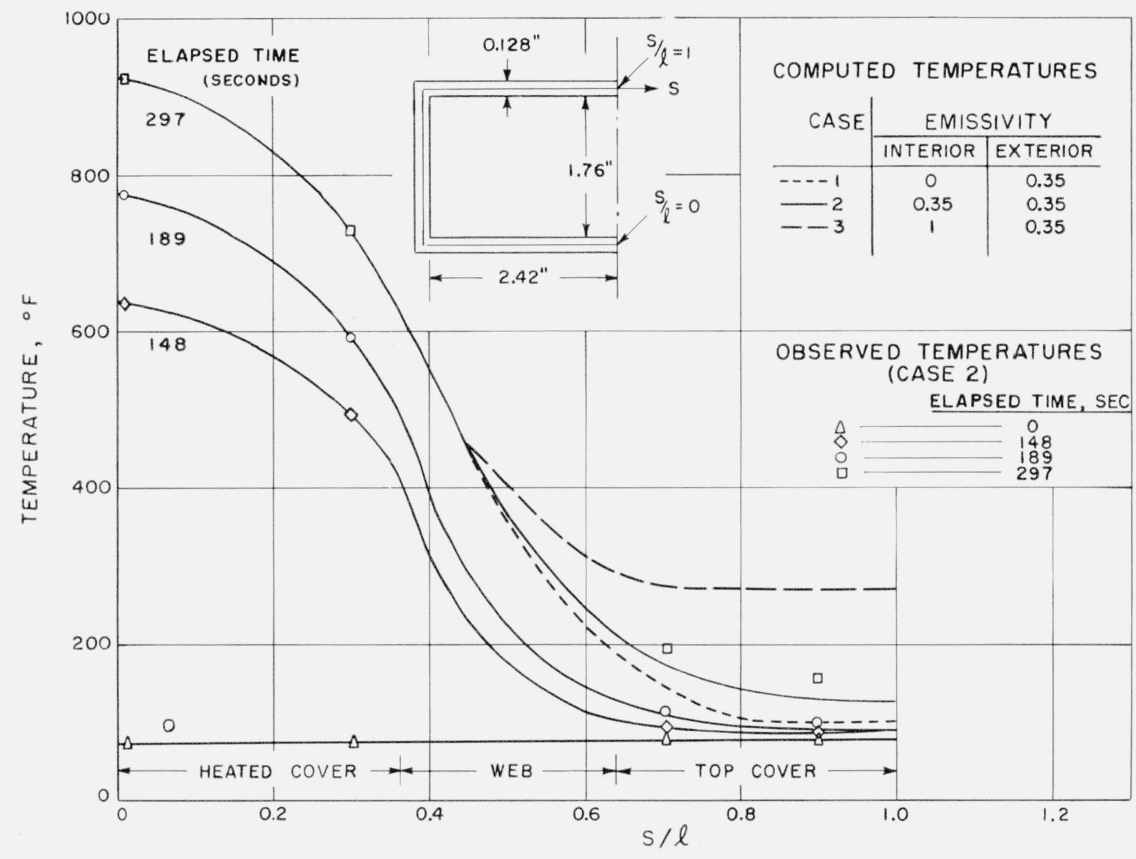

FIGURE 7. Test beam temperature distribution.

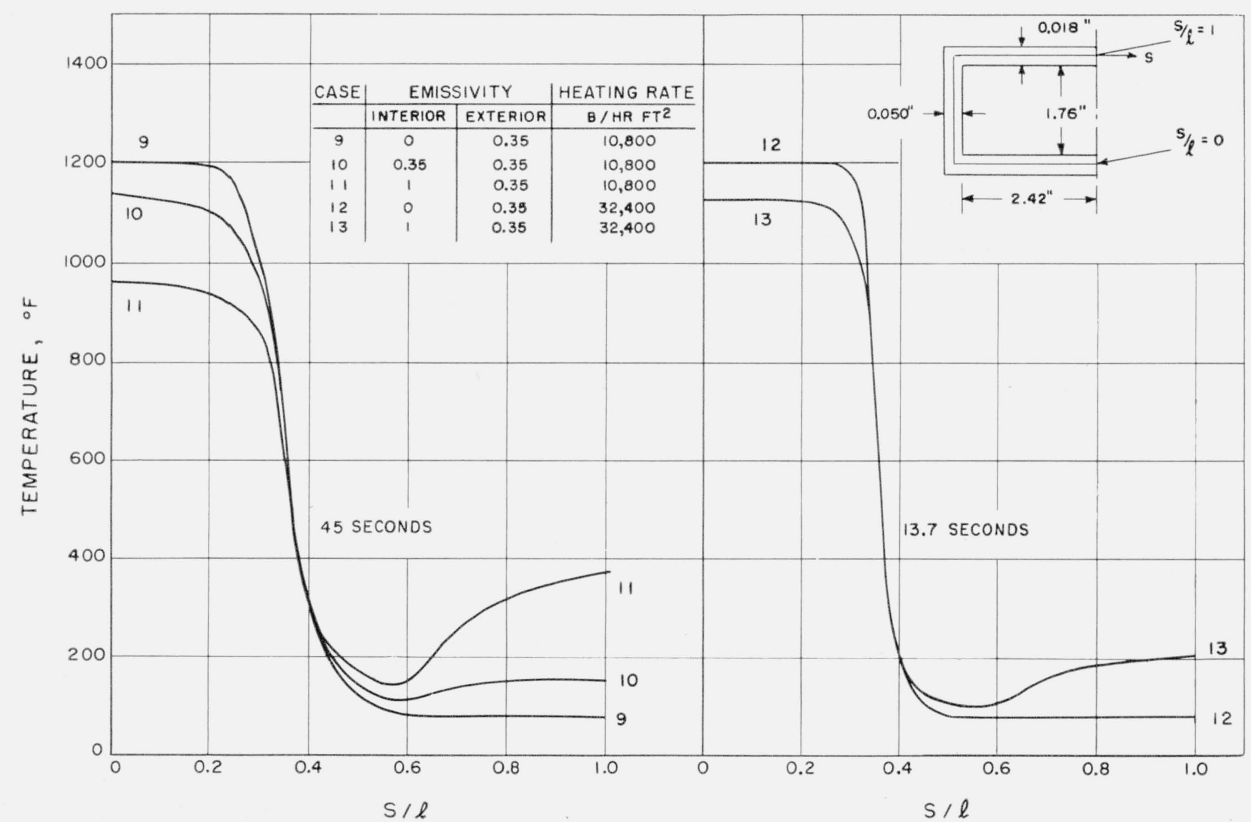

Figure 8. Temperature distribution in thin-walled beam. 


\subsection{Thermal Stress and Deflection}

In order to evaluate the effect of a change in emittance on the thermal stress distribution and deflection, thermal stress distributions and deflections were computed for the 13 cases under the conditions listed in table 1. Maximum tensile stress, maximum compressive stress, and maximum deflection are listed in columns 11, 12, and 13, respectively, in the table. To generalize the results as regards beam length the deflection is given as the deflection per unit beam length squared; the maximum deflection is proportional to the beam length squared, the thermal stresses are independent of the beam length. The possible effects of yielding, creep, and buckling were neglected. Values of the thermal stress and deflection are therefore valid only for comparison purposes.

For a thick-walled, slowly heated beam with heated cover at $958^{\circ} \mathrm{F}$ (cases $1,2,3$ ) a change in the interior wall emittance has little effect on the magnitude of the maximum thermal stress. An increase in the interior wall emittance from 0 to 1.0 however, results in a decrease of 34 percent in the maximum beam deflection. For the beams with the same geometry and under the same heating conditions in which the final heated cover temperature is about $1,200^{\circ} \mathrm{F}$, a change of the interior wall emittance from 0 to 1.0 reduces the absolute maximum stress by from 9 percent (cases 4 and 6 ) to 27 percent (cases 9 and 11), and deflection by from 15 percent (cases 12 and 13) to 40 percent (cases 9 and 11). In the latter beam, the reduction in maximum tensile stress was 31 percent. For a change of the exterior wall emittance from 0 to 1.0 (cases 7 and 8), the reduction in absolute maximum stress was 8 percent, and the reduction in maximum deflection was 7 percent.

For the beams analyzed, changing the interior beam emittance from 0.35 to 1 causes a change in the temperature difference, $d$, between $A$ and $B$ which is about 75 percent of the change that would occur for a change in emittance from 0 to 1 . Corresponding ratios for maximum thermal stress and deflection are about 66 and 74 percent, respectively.

\subsection{Comparison of Experimental and Theoretical Results}

A partial check of the temperature distribution and deflection was made for case 2 using a beam 30 in. long. Computed and observed temperatures for two points on the unheated cover after 148, 189, and 297 secs of heating are shown in figure 7 . Agreement is fair. Some of the discrepancy may be attributed to gas heat transfer within the beam. For the conditions listed under case 2 in table 1 , observed beam deflection was 0.37 in. and beam deflection computed from the theoretical temperature distribution was 0.38 in. i.e., 0.00042 in./(in. length $)^{2}$.

\section{Conclusions}

A change in the interior surface emittance of a box beam heated along one cover has an appreciable effect on the temperature distribution, and consequently on the maximum thermal stress and the deflection. For a variety of beam geometries and heating conditions, a change of the interior surface emittance from 0.35 to 1 for a stainless steel beam reduces considerably the temperature difference from cover to cover in the temperature range above $700^{\circ}$ to $900^{\circ} \mathrm{F}$ and the maximum thermal stress and the deflection in the temperature range above $900^{\circ}$ to $1,200^{\circ} \mathrm{F}$. The effect is particularly marked for a thin-walled slowly-heated beam.

\section{References}

[1] S. Goodman, Radiant-heat transfer between nongray parallel plates, J. Research NBS 58, 37 (1957) RP2732.

[2] G. M. Dusinberre, Numerical methods for transient heat flow, Trans. ASME 67, 703-712 (1945).

[3] D. C. Hamilton and W. R. Morgan, Radiant interchange configuration factors, NACA TN 2836 (December 1952)

[4] W. H. MeAdams, Heat iransmission, 3d ed. (McGrawHill Book Co., Ine., New York, N.Y., 1954).

[5] S. Levy, Thermal stresses and deformations in beams, Aeronaut. Eng. Rev, 15, 62-70 (1956).

Washington, December 2, 1958. 


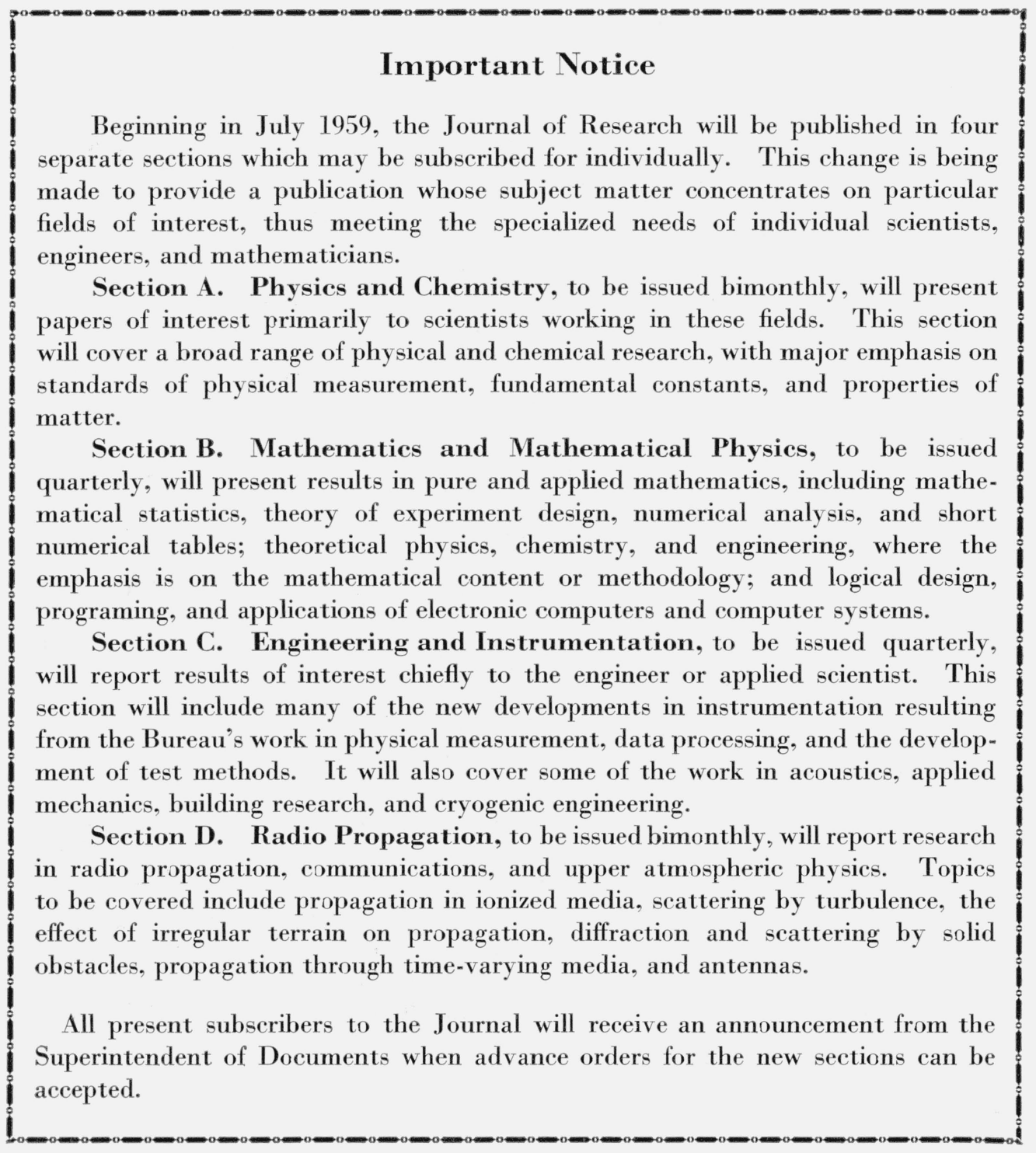

